\title{
Global view on functional foods: Asian perspectives
}

\author{
S. Arai* \\ Department of Nutritional Science, Tokyo University of Agriculture, 1-1-1 Sakuragaoka, \\ Setagaya-ku, Tokyo 156-8502, Japan
}

\begin{abstract}
There is an old Chinese thought meaning that medicine and food are isogenic. In Japan, a national research project started to endorse the thought scientifically, with the birth of functional foods that are now known to function to reduce the risk of life-style related diseases. The science gave rise to a national policy in which some functional foods were legally approved in terms of Foods for Specified Health Use. China has also constructed a unique system for approving some functional foods. This paper pinpoints a recent trend of functional foods characteristic to Asia, with special reference to relevant topics in Japan.
\end{abstract}

Functional foods: Japan: Health: FOSHU

\section{Introduction}

The term 'physiologically functional food', which first appeared in Nature news in 1993 with the headline 'Japan explores the boundary between food and medicine' (Swinbanks \& O’Brien, 1993), gave a strong international impact. Neither the terminology nor the concept of 'functional food' had existed until nine years earlier. In 1984, an ad hoc research group started a systematic, large-scale national project under the sponsorship of the Ministry of Education, Science and Culture (MESC) to explore the interface between food and medical sciences (Arai, 1996). It seems that the realization of this research event first in Japan reflects an underlying thought in the minds of Japanese people throughout history, which originates in the ancient Chinese saying: 'Medicine and food are isogenic'.

However, the advent of modern food science in Japan, which took place about 100 years ago, made its subsequent research proceed towards a purely nutritional rather than a medical science. Especially in the early twentieth century, the nutritive value of foods was of great academic concern. A number of scientists in the field of chemistry as well as food science made particular efforts to discover new nutrients.

More than 10 years after World War II, nutritional problems due to food shortage were almost solved in many countries and a new period characterized by high economic growth began. It prevailed in the time encompassing the 1960s, when the social climate focused on food preference and aversion. Such a trend of hedonism led to academic studies on the sensory properties of foods. Epoch-making advances in instrumental analysis assisted the studies greatly. Japan, among many developed countries, thus contributed to two mainstays of food science: nutrition and hedonics. In accordance with this, food industries were activated to supply a great deal of nutritionally and sensorily acceptable products to the market. We enjoyed thus our rich dietary life for a long time until almost 20 years ago, when a new, antithetic situation arose.

\section{Functional food science and policy born in Japan}

In the 1980s, as the ageing society began to manifest itself in many countries of the world, prompt increases in the so-called life-style related diseases became a matter of public concern. Growing awareness was then observed of the need for eating to beat the odds. The purpose was to prevent life-style related diseases such as diabetes, arteriosclerosis, osteoporosis, allergies, cancer, and even some kinds of infectious diseases, through improved dietary practices in daily life. This gave a strong impetus to food science in Japan. In 1984, the above-mentioned MESC project entitled Systematic Analysis and Development of Food Function commenced, where the terminology and the concept of 'functional food' were first proposed. It was followed by a second project (1988-1991) entitled Analysis of Body-modulating Functions of Foods. In 1992, the last in the series of MESC 'functional foods' projects was realized, focusing on Analysis and Molecular Design of Functional Foods. A total of 60 academic professionals participated, most from medical as well as food science fields. 
In this project, several interesting results were obtained. In particular, research into novel phytochemicals elucidated the occurrence of new anticarcinogens, e.g. fucosterols in seaweed and auraptenes in citrus fruits. The discovery and characterization of potent antioxidants of plant origin, e.g. curcuminoids in ginger, were also reported. Another unique example was offered by oryzacystatin, a cysteine proteinase inhibitor found in the rice, Oryza sativa L., which was molecularly cloned (Abe et al. 1987) and demonstrated to inhibit the proliferation of human herpes virus in infected animal cells (Aoki et al. 1995). These studies were aimed at finding factors with body-defending rather than body-modulating functions.

For body modulation, food allergies and countermeasures were studied extensively. The background was that rice-associated allergy in the form of atopic dermatitis was increasing continually in Japan, a major riceconsuming country, and countermeasures were needed urgently. In response to such a social need, an experiment was undertaken to design and produce hypoallergenic rice grains by enzymatic hydrolysis of main allergenic proteins occurring in the globulin fraction. The development of well-controlled conditions for the hydrolysis gave an immunologically and clinically satisfactory product (Watanabe et al. 1990) and the production process was industrialized to manufacture it. 'Fine Rice' was approved as the first Food for Specified Health Use (FOSHU) product (described below) after careful intervention tests in many medical centres. These basic and applied studies were followed by the discovery and characterization of soyabean and wheat allergens to develop hypoallergenic soyabean and flour products (Tanabe et al. 1996).

The orthodox way of producing functional foods is to maximize beneficially functional factors that are responsible for modulation of the immune, endocrine, nerve, circulatory or digestive system in the body. Sometimes, however, a unique approach can be adopted. Uniqueness is found in minimizing non-beneficial functional factors by enzyme technology or even genetic engineering. The importance of using this concept for the design and production of functional foods has been emphasized since 1984 when the first project began.

The Japan Ministry of Health and Welfare in 1991 initiated the world's first policy of legally permitting the commercialization of selected functional foods in terms of FOSHU, as mentioned above. The new policy is defined by new legislation and also characterized by approving the presentation of a health claim for each FOSHU product. Such legal framework is also expected to hinder the presentation of ill-defined and misleading advertisements in commercial products. Thus, since 1993, some selected food products have been approved to claim a certain degree of medical representation never before permitted for any food. The first was hypoallergenic rice grains ('Fine Rice' by commercial name) developed after extensive immunological studies in the MESC project, produced by enzyme technology and industrialized after clinical intervention tests (Watanabe et al. 1990). A great many FOSHU products have been approved up to now (Table 1).

\section{Glance at Asian functional foods}

Asian food processing is characterized by fermentation. This is reflected in the production of functional foods as well. Actually, FOSHU items (Table 1) include fermented milk, which originates in Caucasus and is produced industrially for particular purposes. A good example is offered by a FOSHU product in which reasonable amounts of the lacto-tripeptides Val-Pro-Pro and Ile-Pro-Pro, angiotensin-converting enzyme inhibitors, have been derived from $\beta$-casein by lactic acid bacteria. Another interesting example is provided by fermented soyabean, natto by Japanese name, which has long been consumed in some Asian districts as well as in Japan. Very recently, a mutant of Bacillus natto was developed that can produce a high quantity of menaquinone-7 (vitamin $\mathrm{K}_{2}$ ) as a cofactor of $\gamma$-glutamic acid carboxylase for biosynthesis of the Ca-carrying protein, osteocalcin. The natto produced using this mutant is thus expected to reduce the risk of osteoporosis and was approved as a FOSHU product. Also, rice whose wild species per se can be found in a district near Tibet is often used as a material for fermentation. In Japan, it was found that a rice bran extract treated with a mixed Lactobacillus-Saccharomyces culture produces a large amount of $\gamma$-aminobutyric acid as a functional food factor for reducing the risk of neural disorders as well as hypertension, although the product remains to be approved.

In China as well, the functional food policy has made a good progress. Chinese functional foods are legally approved, with the logo, in sky blue colour, issued by the Ministry of Public Health. The functions to be considered include twenty-four items as follows (Yi et al. 1999):

1. immune regulation,

2. postponement of senility,

3. memory improvement,

4. promotion of growth and development,

5. anti-fatigue,

6. body weight reduction,

7. oxygen deficit tolerance,

8. radiation protection,

9. anti-mutation,

10. anti-tumour,

11. blood lipid regulation,

12. improvement of sexual potency,

13. blood glucose regulation,

14. gastrointestinal function improvement,

15. sleep improvement,

16. improvement of nutritional anaemia,

17. protection of liver from chemical damage,

18. lactation improvement,

19. improvement for beauty,

20. vision improvement,

21. promotion of lead removal,

22. removal of 'intense heat' from the throat and moistening of the throat,

23. blood pressure regulation and

24. enhancement of bone calcification.

For some categories among these, a variety of foods are considered to be approved (Table 2). These foods are also 
Table 1. Data on 252 foods for specified health uses

\begin{tabular}{|c|c|c|c|}
\hline Health claim* & Functional factor & $\begin{array}{l}\text { Number of products } \\
\text { approved } \dagger\end{array}$ & $\begin{array}{l}\text { Forms of products on } \\
\text { the market }\end{array}$ \\
\hline \multirow[t]{26}{*}{1} & Prebiotics & 61 & \\
\hline & Lactosucrose & 22 & $\begin{array}{l}\text { Soft drink, yoghurt, biscuit, cookie, } \\
\text { table sugar }\end{array}$ \\
\hline & Fructo-oligosaccharides & 15 & $\begin{array}{l}\text { Table sugar, tablet candy, pudding, } \\
\text { soyabean curd }\end{array}$ \\
\hline & Soyabean oligosaccharides & 9 & Soft drink, table sugar \\
\hline & Xylo-oligosaccharides & 5 & Soft drink, vinegar, chocolate, tablet candy \\
\hline & Galacto-oligosaccharides & 4 & Table sugar, vinegar \\
\hline & Isomalto-oligosaccharides & 3 & Table sugar \\
\hline & Raffinose & 1 & Powdered soup \\
\hline & Lactulose & 1 & Soft drink \\
\hline & Arabinose & 1 & Table sugar \\
\hline & Probiotics & 49 & \\
\hline & Lactobacillus casei Shirota & 26 & Lactic acid bacterium drink \\
\hline & Lactobacillus delbrueckii and Steptococcus salivarius & 6 & Fermented milk \\
\hline & Bifidobacterium lactis & 4 & Yoghurt \\
\hline & Bifidobacterium breve Yakult & 4 & Fermented milk \\
\hline & Lactobacillus rhamnosus GG & 2 & Fermented milk \\
\hline & Bifidobacterium longum & 4 & Fermented milk \\
\hline & Lactobacillus acidophilus and $B$. longum & 3 & Fermented milk \\
\hline & Dietary fibres & 58 & \\
\hline & Indigestible (resistant) dextrin & 28 & Sausage, cookie, drink, miso soup, curd \\
\hline & Psyllium husks & 21 & Powdered drink, noodle, cereal \\
\hline & Wheat bran & 2 & Cereal \\
\hline & Galactomannan & 1 & Jelly \\
\hline & Partially hydrolysed guar gum & 3 & Powdered drink, boiled rice \\
\hline & Agar & 2 & Noodle, jelly \\
\hline & Beer yeast & 1 & Fermented milk \\
\hline \multirow[t]{4}{*}{ II } & Soya protein and peptide & 17 & $\begin{array}{l}\text { Soft drink, humbug, meat ball, sausage, } \\
\text { soya milk }\end{array}$ \\
\hline & Low-molecular-weight sodium alginate & 7 & Soft drink, soup \\
\hline & Chitosan & 3 & Biscuit \\
\hline & Sitosterol ester & 1 & Margarine \\
\hline \multirow[t]{6}{*}{ III } & Peptides & 20 & \\
\hline & Sardine peptides (containing VY) & 9 & Soft drink, soup \\
\hline & Lacto-tripeptides (VPP and IPP) & 5 & Lactic acid bacterium drink \\
\hline & Dried bonito oligopeptides (containing IKP) & 2 & Fermented soyabean soup \\
\hline & Casein dodecapeptides (FFVAPEPEVFGK) & 4 & Soft drink \\
\hline & Eucommia leaf glycoside (geniposidic acid) & 2 & Soft drink \\
\hline \multirow[t]{2}{*}{ IV } & Diacylglycerol & 5 & Cooking oil \\
\hline & Diacylglycerol and sitosterol & 4 & Cooking oil \\
\hline \multirow[t]{5}{*}{ V } & Casein phosphopeptide & 7 & Soft drink, chewing gum, soyabean curd \\
\hline & Calcium citrate malate & 3 & Soft drink \\
\hline & Heme & 4 & Soft drink, jelly \\
\hline & Menaquinone-7 producing Bacillus subtilis & 2 & Fermented soyabean (natto) \\
\hline & Soya isoflavone & 1 & Tea drink \\
\hline \multirow[t]{3}{*}{ VI } & Manitol, palatinose and tea polyphenols & 3 & Chocolate, chewing gum \\
\hline & Manitol & 2 & Candy \\
\hline & Xylitol & 1 & Chewing gum \\
\hline \multirow[t]{3}{*}{ VII } & Wheat albumin & 2 & Powdered soup \\
\hline & Globin digest & 1 & Soft drink \\
\hline & Guava polyphenols & 1 & Soft drink \\
\hline
\end{tabular}

*Claim I, foods that improve gastrointestinal conditions; Claim II, foods for those with high serum cholesterol; Claim III, foods for those with high blood pressure; Claim IV, foods for those with high serum triacylglycerol; Claim V, foods related to mineral absorption and transport; Claim VI, non-cariogenic foods; Claim VII, foods for those who begin to feel concerned about their blood sugar level. † As of 29 May 2001.

used as medicines. Thus, distinguishing between foods and traditional medicines is not an easy task. The difficulty apparently reflects the Chinese tradition that medicine and food share a common origin.

Some food factors may be studies for purely medical rather than food use. In an extensive screening study covering common vegetables and fruits in south-east Asian countries, anti-tumour promoting potential, detected by the inhibitory rate of tumour promoter-induced EpsteinBarr virus activation, was generally higher in the plants from tropical zones than in those from Japan. Moreover, plants in the families Zingiberaceae, Rutaceae, Labiatae and Cruciferae, which are used as traditional medicines, were shown to contain potent anti-tumour promoters at high rates (Arai et al. 2001). For functional food scientists, Asia may thus be like a treasure house. 
Table 2. Representative Chinese functional foods for body modulation in specified categories (Yi et al. 1999)

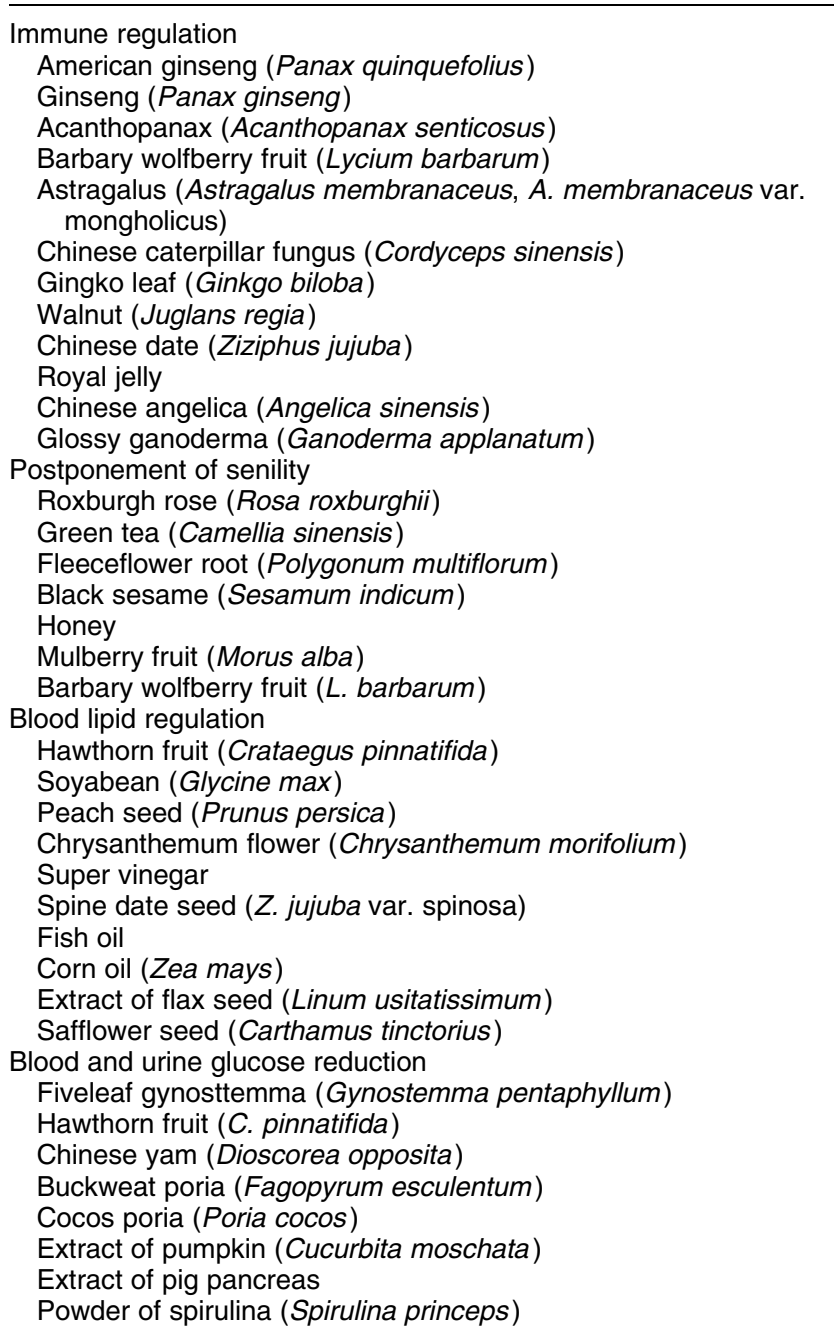

\section{International view on functional food science and policy}

Meanwhile, the implementation of the Ministry of Health and Welfare's FOSHU policy as well as the initiation of functional food science in Japan had a strong impact on many countries of the world, particularly in Europe. Early in 1995, the UK Ministry of Agriculture, Fisheries and Food defined, though temporarily, functional foods as those that had components incorporated to give specific medical or physiological benefits, other than nutritional effects (Richardson, 1996).

Deeper interest was paid by the European body of the International Life Sciences Institute (ILSI Europe). ILSI Europe addressed the present status by claiming that we stand today at the threshold of a new frontier in nutritional science, and also stating that the concept of food is changing from a past emphasis on eating to get rid of hunger into a current emphasis on promising uses of foods to reduce the risk of chronic illness (Bellisle et al. 1998). This new concept is of extreme importance in view of the demands of the elderly population for improved quality of their late life, increases in life expectancy and costs for health care, and technical advances in the food industry.

As recognized in the Japan MESC research project, up-to-date knowledge in the biosciences, including biochemistry and molecular biology together with sophisticated biotechnologies based on these, supports the hypothesis that foods can modulate various functions in the body and thus participate in the maintenance of a state of health that reduces the risk of life-style related diseases. Such a hypothesis exists at the origin of the concept of 'functional food' for the development of a new discipline, 'functional food science', in Europe as well as in Japan.

What may be most important at present is to evaluate the function. Since any functional food must be based on science, its evaluation should essentially depend on data from biochemistry, physiology, molecular and cell biology, and other most modern biosciences. A key approach to the development of a functional food is the identification and validation of relevant markers, including biomarkers that can predict potential benefits relating to a target function in the body. If the markers represent an event directly involved in the process, these should be considered as functional factors. On the other hand, if the markers represent correlated events, they should be considered as indicators. In detail, possible markers have been tentatively listed in relation to target functions (Diplock et al. 1999).

There are many options for selecting appropriate markers. A promising option may be the use of accumulated knowledge about genomics. As the human genome project has been completed (Venter et al. 2001), the socalled post-genomics, involving the use of genomics data, will follow, which may not be unrelated to functional food science. A number of sophisticated biotechnologies will become available, one of the most useful being DNA tip technology (Marton et al. 1998). It is helpful because of its high throughput potency to assess the possible effects and safety of functional food factors by total gene expression profiles.

Current genome programmes are proceeding on food organisms as well. These include rice, wheat, corn, soyabean, and other major plant seeds for food use. A variety of post-genomics sciences, to be born shortly before and after the completion of the genomics, will lead to the development of new biosciences such as nutrigenomics. The development will support advances in proteomics, providing key information about the molecular design of functional food proteins. It will thus be possible to easily define their specific functional regions involved in the prevention of such life-style related diseases as diabetes, hypertension, hypercholesterolaemia, allergies, cancer and even infectious diseases. Among a number of trials, proteomics for the design of antiviral proteins may serve as an example. One such study involves a threedimensional NMR analysis of solution structures of oryzacystatin, an anti-herpes protein of rice origin described above (Abe et al. 1987; Aoki et al. 1995). The analysis 
provides information about the minimal effective region (Nagata et al. 2000), the use of which will contribute to molecular breeding of new rice cultivated with an antiviral function.

It is also noted that an ad hoc team headed by the present author (S.A.) has begun to make a database of functional foods under the sponsorship of the Japan MESC.

Finally, it is stressed that Asian people have always recognized the importance of sensory properties of foods. They still think that every food must be sensorily acceptable. Even functional foods cannot be ruled out. The science should include studies on the senses of taste and smell. The significance of this is emphasized since such sensations have been found to be related more or less to functions of the endocrine and exocrine systems, as well as to those of the digestive system. An interesting example can be found in red pepper, whose unique irritative component, capsaicin, has a 'hot' flavour in seasoning. This substance, shortly after entering the body per os, interacts with vanilloid receptors such as $\mathrm{Ca}$ channels in sensory neurons inducing a specific dynamic action, possibly with an anti-obesity result. Capsaicin can thus be regarded as a functional factor with such a bilateral effect. Sensory abnormalities and disorders are other targets of functional food science, because insights into syndromes of these kinds will supply patients with organoleptically acceptable tailormade foods having body-modulating functions at the same time.

The design and development of functional foods should not be carried out independently of purely nutritional and sensory or cognitive properties of foods. Future advances in relevant sciences for giving rise to foods with integral attributes would distinguish functional foods from medicines. Research along this line will add a newer dimension to functional food science and will also be academically and socially understood as having great potential for the development of new food science, technology and industry in the early twenty-first century.

The reader is advised to consult recently published papers to learn more about the state-of-the-art concerning functional foods (Arai et al. 2001; Kwak \& Jukes, 2001). The former paper is the proceedings of a symposium, A Mainstay of Functional Food Science in Japan History, Present Status, and Future Outlook, which was organized by the Japan Branch of the International Union of Food Science and Technology in collaboration with ILSI Japan.

\section{References}

Abe K, Emori Y, Kondo H, Suzuki K \& Arai S (1987) Molecular cloning of a cysteine proteinase inhibitor of rice (oryzacystatin). Journal of Biological Chemistry 262, 16793-16797.

Aoki H, Akaike T, Abe K, Kuroda M, Arai S, Okamura R, Negi A \& Maeda M (1995) Antiviral effect of oryzacystatin, a proteinase inhibitor in rice, against herpes simplex virus type 1 in vitro and in vivo. Antimicrobial Agents in Chemotherapy 39, 846-849.

Arai S (1996) Studies on functional foods in Japan — states of the art. Bioscience Biotechnology Biochemistry 60, 9-15.

Arai S, Osawa T, Ohigashi H, Yoshikawa M, Kaminogawa S, Watanabe M, Ogawa T, Okubo K, Watanabe S, Nishino H, Shinohara K, Esashi T \& Hirahara T (2001) A mainstay of functional food science in Japan - history, present status, and future outlook. Bioscience Biotechnology Biochemistry 65, $1-13$.

Bellisle F, Diplock AT, Hornstra G, Koletzko B, Roberfroid M, Salminen S \& Saris WHM (editors) (1998) Functional food science in Europe. British Journal of Nutrition 80, Suppl. 1, $\mathrm{S} 1-\mathrm{S} 193$.

Diplock AT, Aggett PJ, Ashwell M, Bornet F, Fern EB \& Roberfroid MB (1999) Scientific concepts of functional foods in Europe: consensus document. British Journal of Nutrition 81, Suppl. 1, S1-S27.

Kwak S \& Jukes DJ (2001) Functional foods, Part 1: the development of a regulatory concept. Food Control 12, 99-107.

Marton MJ, DeRisi JL, Bennett HA, Iyer VR, Meyer MR, Roberts CJ, Stoughton R, Burchard J, Slade D, Dai H, Bassett DE, Hartwell LH, Brown PO \& Friend SH (1998) Drug target validation and identification of secondary drug target effects using DNA microarrays. Nature Medicine 4, 1293-1301.

Nagata K, Kudo N, Abe K, Arai S \& Tanokura M (2000) Three dimensional solution structure of oryzacystatin-I, a cysteine proteinase inhibitor of the rice, Oryza sativa L. japonica. Biochemistry 39, 14753-14760.

Richardson DP (1996) Functional foods - shades of gray. An industry perspective. Nutrition Reviews 54, S174-S185.

Swinbanks D \& O'Brien J (1993) Japan explores the boundary between food and medicine. Nature 364, 180.

Tanabe S, Tesaki S, Yanagihara Y, Mita H, Takahashi K, Arai S \& Watanabe M (1996) Inhibition of basophil histamine release by a haptenic peptide mixture prepared by chymotryptic hydrolysis of wheat flour. Biochemistry and Biophysics Research Communications 223, 492-495.

Venter JC, Adams MD, Myers EW, Li PW, Mural RJ, Sutton GG et al. (2001) The human genome. Science 291, 1304-1351.

Watanabe M, Yoshizawa T, Miyakawa J, Ikezawa Z, Abe K, Yanagisawa T \& Arai S (1990) Production of hypoallergenic rice by enzymatic decomposition of constituent proteins. Journal of Food Science 55, 781-783.

Yi D, Yong P \& Wenkui L (1999) Chinese Functional Food, pp. 19-20. Beijing: New World Press. 